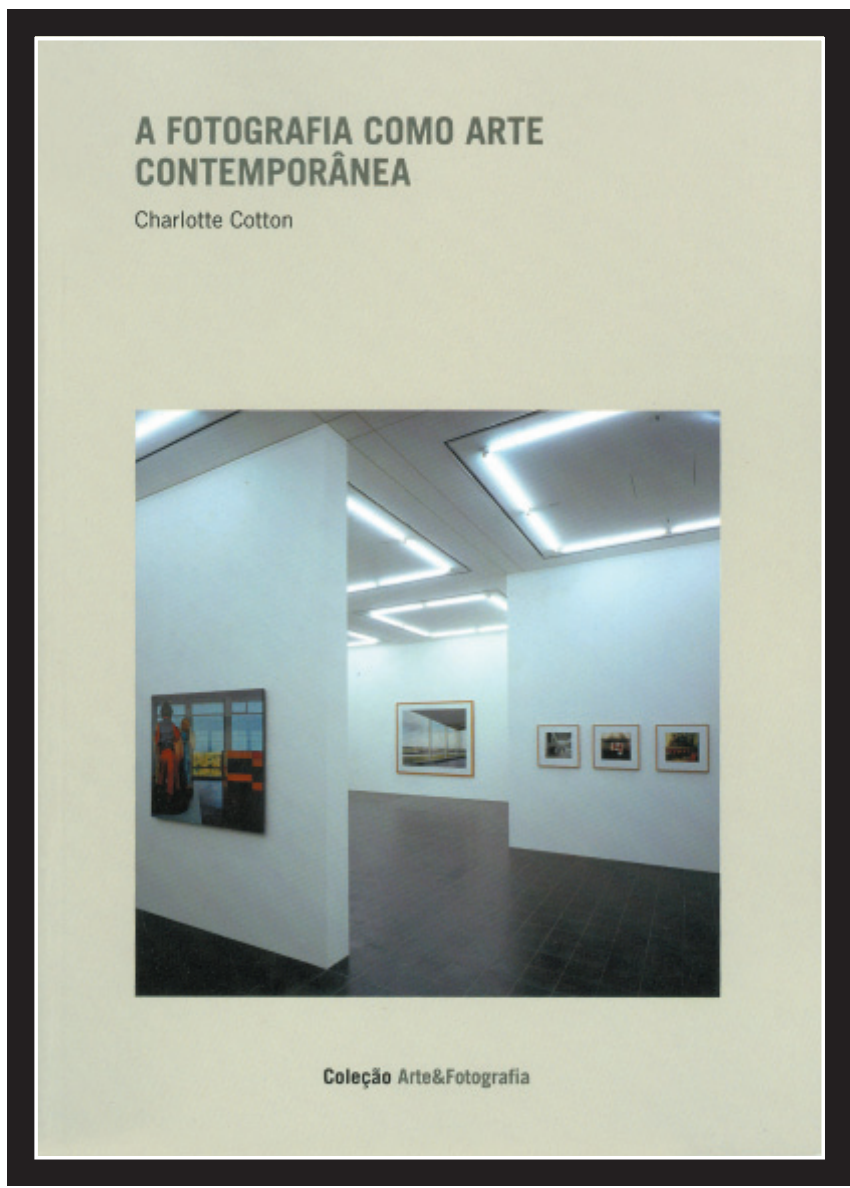

A fotografia como arte contemporânea, de Charlotte Cotton. São Paulo: WMF Martins Fontes, 2010, 248 p. 


\title{
Conceitos possíveis para uma fotografia contemporânea
}

Possibles concepts for a contemporary photography

\author{
Karina Rampazzo Morelli *
}

Diretora de criação do Museu Nacional da Mídia e curadora de diversas exposições fotográficas em Londres, Charlotte Cotton se utiliza de linguagem analítica para escrever A fotografia como arte contemporânea (Martins Fontes, 2010, 248 páginas). Na obra, encontramos novos conceitos e importantes discussões sobre a fotografia no meio artístico. Cada vez mais em evidência no espaço das artes, a fotografia vive seu período de maior efervescência e caminha expressivamente como um veículo de ideias. A partir de uma perspectiva aberta, o livro apresenta artistas-fotógrafos e fotógrafos-artistas de diversas vertentes e, em paralelo, comenta fotografias encontradas tanto em exposições públicas quanto em museus ou galerias de arte pelo mundo todo.

Mesmo dividindo o conteúdo em oito capítulos, a autora trabalha relações entre pontos argumentativos. Cada capítulo se delimita pela escolha de fotógrafos de uma mesma base produtiva ou metodológica. Assim, evitou-se a tradicional divisão por estilo ou tema, muitas vezes determinantes de conceitos fixos e, por ora, desnecessários ao entendimento da fotografia artística contemporânea tão plural.

No primeiro capítulo, intitulado Se isto é arte, os fotógrafos abordados se aproximam da produção fotográfica dos anos 60 e 70, trazendo por registros "acidentais" acontecimentos artísticos, subprodutos de uma ação anterior. O mero documento fotográfico se expande, muitas vezes pré-determinado, para um discurso profundo

\footnotetext{
* Graduada em Programação Visual (Design) pela Universidade Norte do Paraná (Unopar). Especialista em Fotografia pela Universidade Estadual de Londrina (UEL). Mestranda em Comunicação na Universidade Estadual de Londrina. E-mail: karampazzo@gmail.com
} 
entre performances e eventos destinados à câmera. A fotografia de Alfred Stieglitz, feita a partir da Fonte em 1917 de Marcel Duchamp, encaixa-se neste recorte. A imagem é resultado da exposição de um mictório em um salão de arte. A relação - obra/imagem - está fortemente arraigada até os dias de hoje. Como exemplo de trabalho mais atual, o artista Oleg Kulik fez referência ao artista alemão Joseph Beuys, fotografando sua própria performance Eu mordo os Estados Unidos e os Estados Unidos me mordem.

Na sequência, em Era uma vez, a narrativa de uma história através do uso da fotografia é trazida em discussão. Os fotógrafos, com influência da era pré-fotográfica dos séculos XVIII e XIX, fazem referências a fábulas, lendas e mitos presentes desde então no imaginário coletivo moderno. Descrita como fotografia de quadros (tableau photography) ou quadros-vivos (tableau vivant photography), a narrativa se concentra em uma única fotografia. $\mathrm{O}$ trabalho $O$ caminho de casa, de Tom Hunter (2000), é um ótimo expoente dessa estética. Inspirado nas pinturas de Jan Vermeer (163275), o artista reproduz pela fotografia a essência da obra aplicada em outro contexto. Revisitando temas e obras da história da arte criou-se novas possibilidades presentes na arte contemporânea.

O capítulo seguinte se dedica à reflexão das chamadas fotografias Inexpressivas, ou seja, fotografias artísticas com características em comum, como o uso de ausência dramática ou de hipérbole visual, termos utilizados pela autora. Estas imagens são paisagens vazias, cidades desertas ou lugares sem importância alguma com pessoas anônimas. As imagens de Andreas Gursky estão neste capítulo e completam o discurso da inexpressividade. Com superficialidade técnica, ele é descrito como um observador de sua própria perspectiva - construída por imagens de paisagens distantes, sítios industriais, bolsa de valores, estádios esportivos e hotéis. O público, quando da visita às grandes impressões digitais nas galerias, pode ficar ainda mais distante dos temas selecionados e, ironicamente, próximo de uma ação imagética. 
Em Alguma coisa e nada, são debatidos os fotógrafos contemporâneos que ultrapassam os limites de um tema visual. Em um contexto totalmente possível de acontecer, os registros fotográficos tendem a incluir espaços ou mesmo objetos completamente normais, sem qualquer destaque. O que se ignora, aqui é apreciado. Naturezasmortas, cenas internas de casas, detalhes de objetos, constituem imagens aparentemente interrompidas ou inacabadas, tornando por fim, diferente a forma de encarar a vida cotidiana. O menor dos temas é transformado pela fotografia em um patamar de importância e imaginação. O trabalho de Peter Fischli e David Weiss, de 1984, ajuda a compreender toda base desse conceito: uma série de fotografias de naturezas-mortas reúne objetos comuns fixados em combinações improváveis, transitando por um território mais lúdico, mesmo ligado ao banal.

A fotografia se condensa na exposição das relações pessoais em Vida íntima. Com informalidade e amadorismo técnico, as imagens são geradas dentro de ambientes familiares. Esta linguagem doméstica e instantânea - também presente nos equipamentos fotográficos (com o uso, por exemplo, de câmeras Instamatic em alguns projetos ) traz o meio privado para o público sem limites ou preceitos. A vida cotidiana explicitada nos meios de comunicação, sem qualquer controle especial, pode ser encontrada nos trabalhos de Richard Billingham, datados de 1994. Neles, o artista fotografa cenas do seu próprio cotidiano, deixando às claras os relacionamentos e acontecimentos de sua família.

Momentos na história segue no mesmo fôlego e traz "fotografias das consequências", ou seja, fotografias documentais e paralelamente artísticas que presenciaram acontecimentos do mundo. Sem esquecerse de sua importância social, as imagens ampliam um olhar diferente e, com qualidade de produção, circula em lugares de confronto, cidades em conflito ou desamparadas. Sobre as mazelas de uma história existe um olhar mais expressivo e, por que não, poético. Este capítulo traz 
um conjunto de trabalhos fotográficos que provocam os limites da fotografia meramente documental.

A análise pós-moderna possibilita alternativas de compreensão de sentido nas fotografias contemporâneas. Este é o mote de Revivido e refeito, sob a ótica de pensadores como Roland Barthes (19151980) e Michel Foucault (1926-1984), no qual a autora teoriza sobre o significado de qualquer imagem que não seja produzida com o intento do autor, mas sim determinada em referência ao conjunto de imagens ou signos de uma cultura ou civilização. Imagens que alimentam o espectador em seu repertório imagético e o faz construir outras imagens por referências associativas. Vik Muniz, com seus trabalhos de 1997, é um bom exemplo dessa linguagem. Neles, o artista desenhou em calda de chocolate e depois fotografou uma cópia da fotografia do pintor expressionista abstrato Jackson Pollock, tomada por Hans Namuth. Assim se reconhece na fotografia o desenho, o quadro e o fotógrafo em um ciclo curioso entre imagens, referências e memória.

Físico e material, o último capítulo, foi influenciado pelo ensaio de 2006 da artista Tacita Dean sobre os pontos comparativos entre a fotografia analógica e a tecnologia digital. A fotografia analógica funcionaria como uma iniciativa envolvendo escolhas positivas e valorizando a materialidade deste meio de expressão, como uma retomada às raízes da fotografia. Também vale citar a questão da internet como meio de encontrar outros públicos e superando todos os limites.

Durante toda a leitura percebe-se nitidamente que a fotografia artística contemporânea não se sustenta apenas na ideia de autorreferência ou passado histórico. Charlotte Cotton expõe as muitas linguagens fotográficas para marcar, pontualmente, a (ou uma) obra de determinado artista, mas, simultaneamente, amplia suas possibilidades expressivas à medida que comenta e encaixa a imagem em contextos maiores.

O livro se destina especialmente aos públicos das artes e da comunicação, além de fotógrafos e designers e, claro, a todos os 
interessados pelas vertentes contemporâneas do pensamento em torno da imagem. Com ele, abrem-se perspectivas complementares para a construção de novos significados em um tema tão expressivo, apesar de recente. 